\section{Cultural Challenges in Implementing Palliative Care Services in Jordan}

\author{
Khaled Khader, RN, PhD* \\ Faculty of Nursing, Taif University, Taif 26571, Al Huwaya, Saudi Arabia
}

"Corresponding author
Khaled Khader, RN, PhD

Assistant Professor

Faculty of Nursing

Taif University, Taif 26571

Al Huwaya, Saudi Arabia

E-mail: khaledkhader@yahoo.com

\section{Special Edition 1}

Article Ref. \#: 1000PMHCOJSE1114

\section{Article History}

Received: April $6^{\text {th }}, 2017$

Accepted: July $10^{\text {th }}, 2017$

Published: July $12^{\text {th }}, 2017$

\section{Citation}

Khader K. Cultural challenges in implementing palliative care services in Jordan. Palliat Med Hosp Care Open J. 2017; SE(1): S68-S72. doi: 10.17140/PMHCOJ-SE-1-114

\section{Copyright}

(C)2017 Khader K. This is an open access article distributed under the Creative Commons Attribution 4.0 International License (CC BY 4.0), which permits unrestricted use, distribution, and reproduction in any medium, provided the original work is properly cited.

\section{ABSTRACT}

Palliative care in Jordan is considered to be advanced in comparison to that of other Middle East countries. According to Jordanian leaders of palliative care, Jordan is not different from advanced countries in applying principles and approaches of palliative care. There are many cultural challenges hinder provision of these services. First, fear of addiction by patients, family and healthcare providers prevent them from providing adequate pain management. Second, lack of adequate knowledge regarding pain management among healthcare providers is also a great challenge. In addition, health policies and inadequacy of palliative services make the problem worse. Third, fear of family and physician to refer patients to palliative care as it is considered to be failure of treatment. Fourth, lack of family participation in most medical and end-of-life decisions deprive patients from receiving proper palliative care. Finally, religious misconceptions force patient to suffer pain to an intolerable level and prevent them from seeking immediate medical help. To overcome these challenges, it is recommended to improve palliative health policy at national level, include palliative care materials in health curriculum, raise public awareness of palliative care, and provide more opportunities for palliative training and research.

KEY WORDS: Palliative care; Cultural challenges; Health policy; Jordan; Pain management; Addiction; Religious.

\section{INTRODUCTION}

Jordan has 4,600 new adult cancer cases per year. More than $60 \%$ of all the present cases cancer are received in a late stage which severely need palliative care. ${ }^{1}$ Palliative and hospice care were first provided by a non-governmental organization, the Al-Malath Foundation. It provided palliative care services to a limited number of patients in the capital of Jordan. ${ }^{1}$ At the present time, the majority of specialized palliative, hospice and home care services are offered by the King Hussein Cancer Center (KHCC). Both palliative and hospice care are introduced in one ward with no separation between them. Other institutions that treat cancer patients do not have specialized palliative care units or interdisciplinary palliative care teams (e.g., Ministry of Health Hospitals, Royal Medical Services). ${ }^{2}$

Palliative care programmes in Jordan have been growing with the support of the World Health Organization (WHO) and Jordan Ministry of Health. ${ }^{3}$ Palliative care services in Jordan developed better than that of most of its neighbors in the Middle East but lagging behind advanced countries. Like many other countries, palliative and end-of-life care in Jordan is provided mainly to cancer patients. ${ }^{4}$ The palliative care program was started in 2004 at KHCC. It is limited to adult patients in Amman, the capital of Jordan. There was severe deficiency in patient support services such as palliative care, nutrition, psychosocial support and rehabilitation. ${ }^{5}$ The provision of standardized palliative and home care by one center is considered as the major problem, and besides that not all cancer patients have the chance for admission due to logistic issues, financial issues, or the lack of vacancies in the center. ${ }^{6}$ The number of beds and healthcare providers are limited. In addition, the KHCC budget is mostly based on financial 
aids from national and international agencies.

Palliative and hospice principle care is practiced and applied in Jordan like any other advanced country. Jordanian people have no differences in their reaction to terminal illness and their experience of suffering. Therapeutic communication skills, effective symptom management and effective end-of-life care are necessary skills in any palliative program.

Dr. Mohammad Bushnaq, president of the Jordanian Palliative Care and Pain Management Society, presented a case study in Jordan in 2008 and assured that approaches developed in Europe and the United States can be integrated into traditional Arab culture. He also added that values and principles of palliative care are same everywhere, but the way we apply it needs to be tailored to local culture and norms. This is also supported later by Dr. Omar who said that there are many similarities of practice between the US and Arab country's palliative care services, like in Saudi Arabia or Jordan or any other Arab country. They are similar in using opioids, withdrawing and withholding some unnecessary interventions and applying "do not resuscitate" order. The only thing which is forbidden for Islamic rule is euthanasia which is allowed and practiced in some parts of the US. $^{7}$

\section{BARRIERS TO PALLIATIVE CARE}

There are many challenges hinder the provision of palliative care. One of the effective barriers on the flow and development of providing standardized palliative care is cultural barriers. Some of these related to healthcare providers, patients, and healthcare settings. ${ }^{6}$ Other barriers are related to policy and legislation, clinical practice, education, and research. ${ }^{2}$

\section{CLINICAL PRACTICE}

The major barriers that are associated with the healthcare providers include:

- Delay in referrals, due to physicians' denial of the need to refer and the sense of failure, palliative care as a discipline is being seen as less prestigious and caregivers are often uncomfortable caring for terminal patients. ${ }^{1}$ Delay of referring patients to the palliative care because many physicians (e.g., oncologists) still equate palliative care with hospice care.

- Truth concealment from cancer patients is still common in Jordan especially with elderly cancer patients. Thus, it would be difficult for palliative care nurses to provide quality care to a cancer patient who is not aware of his/her diagnosis and/or prognosis. $^{2}$

- Some Barriers are associated with the palliative care team; the team is not well supported which leads to staff burnout and lack of training. ${ }^{1}$ In Jordan, the role of nurses in pain management is to fulfill physicians' orders without any obvious guidelines. ${ }^{8}$

\section{NARCOTIC AND PAIN MANAGEMENT}

The most dominant one was perception and attitude of patients, family, society and healthcare providers toward narcotic drugs as a pain killer. According to Dr. Bushnaq, Jordan's first international palliative care conference was held in Amman. There he mentioned that $90 \%$ of patients with chronic diseases who need palliative care do not receive it, adding that 10,000 cases out of the 18,000 deaths registered annually in Jordan, die while suffering from pain. ${ }^{2}$

According to the International Narcotics Control Board (INCB) survey of countries where access to controlled medicines such as morphine and methadone is low-to-inadequate, fear of addiction is the main barrier to access. ${ }^{9}$ The same notes were stated by Dr. Bushnaq who considered fear of addiction is one of the most important drawbacks towards provision of palliative care in Jordan. This was supported by a previous study that revealed healthcare providers (physicians and nurses mainly) erroneously believe that taking narcotics means addiction in cancer patients. ${ }^{10}$ The "opioid phobia" was used as a synonym for the fear of addiction. The term was used by Alaa Bashayreh, a master degree registered nurse in an article in the Journal of Pediatric Hematology/Oncology. He defined provider "opioid phobia" as the fear of both addiction and opioid-induced side effects. Fear of addiction is experienced by both patient ${ }^{11}$ and healthcare providers. ${ }^{10}$

The fear of provider may arise from inadequate knowledge about the management of cancer pain, not having adequate training in opioid therapy, not following prescribed guidelines of narcotic use enacted by government and focusing more on treatment of cancer than on pain management. Concerns over nausea, vomiting, constipation and respiratory depression may cause some oncologists to hesitate before continuing opioid therapy. ${ }^{12}$

\section{PALLIATIVE EDUCATION AND RESEARCH}

The lack of palliative care education and training programs is a significant barrier to the development and progress of palliative care in Jordan. ${ }^{13}$ Unfortunately, palliative care services in the Eastern Mediterranean (EM) region are limited and the number of physicians trained in palliative care in the region is well below as per the needs of the population. Physicians and nurses lack the skills needed to support their patients. ${ }^{14}$ Only, few educational and training opportunities exist to this point. ${ }^{2}$

Nurses in Jordan have a lower level of pain management knowledge than that reported worldwide. In Jordan, the role of nurses in pain management is to fulfill physicians' orders without any guidelines. ${ }^{8}$

A previous study result demonstrated knowledge deficit and attitude; nurses underestimated and undertreated patients' pain. ${ }^{8}$ This is related to insufficient pain material in medical programs especially nursing programs. ${ }^{11}$ 
Research on palliative care topics are limited. Most of the publications focused on issues related to pain management. ${ }^{2}$ There are few studies on symptom management, feeling and attitudes of nurses towards death and dying, experience of patient and family towards death and dying.

\section{CULTURAL BELIEFS}

The dominant culture among Jordanians discourages patients, and sometimes prohibits them from receiving opioids, based on religious misconceptions. In Islam, tolerating pain can be rewarded from God and expiate sins..$^{15}$ But Islam encourages seeking treatment and pain reliever as narcotic. ${ }^{11}$ The religion of Islam and the family structure are the most influential factors in shaping the Jordanians' beliefs. Islam is the religion of the majority of the population, thus, with concordance with the Islamic teachings most Jordanians believe that illness and wellness are God's will and religious practices (e.g., prayer, reading holy Quran) are widely used to help people cope with illness especially in case of life threatening illnesses. ${ }^{2}$

A traditional Muslim accepts suffering as a way of atonement of one's sins. This way of handling helps the Muslim cope with the illness and to die in peace with self, God, and others. ${ }^{16}$ Jordanian nurses work with patients among which $97 \%$ of population are Muslims and they believe that suffering is a test from God and a person should tolerate his/her pain and hide it from others. ${ }^{8}$ Moreover, traditional Muslims respond well to euphemisms which mean represent the truth in a different way that can be accepted. ${ }^{16}$ Most are seeking reassurance and empathy rather than information about diagnosis. ${ }^{16}$ Cultural and religious beliefs and practices may be a barrier for cancer patients and care providers are reluctant to talk about death or hospice care. ${ }^{13}$

\section{HEALTH POLICY}

Jordan lacks health policy to develop, improve, and sustain palliative care. ${ }^{2}$ Today, Jordan does not have a national palliative care policy. Thus, with the exception of KHCC, palliative and home care services are not available at the national level leaving a large proportion of Jordanian cancer patients without access to palliative care. ${ }^{2,13}$ Moreover, opioids administration policy in Jordan makes delay in prescription and dispensing, and unnecessary cautions among health providers. ${ }^{11}$ Also, restrictions on the length of opioid prescriptions for outpatients are implemented and followed strictly. ${ }^{13}$ Uneven distribution and coverage of palliative care services always been a barrier to the provision and maturation of a palliative care program in Jordan. ${ }^{13}$ The absence of a multidisciplinary approach to palliative care services is also a barrier. Lastly, the underutilization of other professionals, such as social workers, who could help physicians and patients increase the awareness of palliative care services is an additional barrier.

\section{PUBLIC AWARENESS}

An absence of public awareness of palliative care is a consid- erable barrier. People are not informed about palliative care services and retains myths and misconceptions about palliative care. Moreover, there are absence of government recognition of palliative care as an integral part of the Jordanian healthcare system, and finical support is very limited. ${ }^{13}$

\section{PATIENT AND FAMILY}

The conception of patient's family is another challenge. The family perception of referring a patient for palliative care deprives patients from receiving adequate palliative care. They consider referral as s sign of treatment failure and view physicians as weak healthcare provider.

Decision-making on health issues is considered a social process and many family members (e.g., spouse, children) could be involved in that process. ${ }^{2}$ For example, the order "do-not-resuscitate" has many cultural difficulties. The patient and family feel big burden to choose, and many family members said they would feel guilty if they make that decision. ${ }^{16}$ On the other hand, the patient family is not usually considered a target of medical or nursing care among healthcare providers in Jordan. Thus, to promote palliative care, there is a need for a cultural change that entails considering the family in the care provided to Jordanian patients. $^{2}$

Barriers associated with families include' feeling of alienation and isolation; along with the fear of being neglected by the primary physician, unrealistic expectations of future prognosis, refusal of admission to hospice which is considered as a place of death. ${ }^{1}$ Since the family views palliative care as a sign of "giving up" on the patient, physicians may perceive referring a patient for palliative care as a failure of their medical capability and a sign of loss of prestige when explaining the true situation to patients or their families. ${ }^{13}$

Finally, there are many other cultural challenges to study and overcome. These challenges include increased availability of opioid and access in the peripheral governorates of Jordan, to increase the number of palliative care services in all healthcare settings and to create a hospice and home care national insurance plan to improve access and make these service affordable to all. ${ }^{17}$

\section{RECOMMENDATION}

Palliative care in Jordan is evolving but has far to go. Adequate resources provision, educational programs, credentialed healthcare providers are crucial elements that palliative care in Jordan needs. ${ }^{2}$

It is recommended to build palliative care services into existent primary care systems and hospitals as an approach to build capacity in palliative care in all settings. ${ }^{14}$ The new and better concept is that supportive and palliative care should start at diagnosis of a life-threatening illness and gradually increase while disease-modifying care may decrease. ${ }^{18}$ 


\begin{tabular}{|c|c|}
\hline Barrier & Recommendations \\
\hline Clinical practices & $\begin{array}{l}\text {-Palliative education and training } \\
\text {-Clear health policy }\end{array}$ \\
\hline Narcotic and pain management & $\begin{array}{l}\text {-Improve health policy } \\
\text {-Pain management education } \\
\text {-Increase availability of narcotics }\end{array}$ \\
\hline Palliative education and research & $\begin{array}{l}\text {-All health curricula should have some materials about palliative care } \\
\text {-Conducting research in various palliative and hospice aspects of } \\
\text { Jordanian patients }\end{array}$ \\
\hline Cultural beliefs & -Determining myths and misconceptions and give proper education \\
\hline Health policy & $\begin{array}{l}\text {-Restructuring health policy and stress the importance of palliative care } \\
\text { on a national level. }\end{array}$ \\
\hline Public awareness & -Palliative health education in mass media \\
\hline Patient and family & $\begin{array}{l}\text {-Education cancer patient and family about palliative and hospice care } \\
\text { and support them } \\
\text {-Involving patient and family in all stages of treatment. }\end{array}$ \\
\hline
\end{tabular}

As remedy, the government must first adopt a national palliative care program which should be implemented in all the healthcare settings in the country. Once this policy gets formulated and implemented, several barriers to palliative care in general and palliative care nursing in particular would be resolved. ${ }^{2}$

Because of the absence of a national policy on palliative care, palliative care nursing is not included in the undergraduate or post-graduate curricula of many nursing schools in Jordan. ${ }^{2}$ Introducing palliative care courses on the undergraduate level for all medical studies, postgraduate studies and subspecialty training is urgently needed.

Lastly, research in the palliative care field should be encouraged and funded to enable a continuous evaluation of our progress and to reduce the suffering of cancer patients as the ultimate goal of the healthcare system. ${ }^{13}$

Mass media campaigns to increase public awareness about palliative and end-of-life care are on the top priorities. It is important to declare Islam opinion about meaning of suffering and disease and treating pain. Overcoming health and religious misconception of public will greatly support palliative care. Barriers to palliative care and recommendations are summarized in Table 1.

\section{REFERENCES}

1. Gultekin M, Fahmi R, Mostafa K, Khleif A. Palliative cancer care in Middle Eastern countries: Accomplishments and challenges. Ann Oncol. 2012; 23: 15-28. doi: 10.1093/annonc/ mds084

2. Omran S, Obeidat R. Palliative care nursing in Jordan. $J$ Palliat Care Med. 2015; S4: 005, 1-4. doi: 10.4172/21657386.1000S4005
3. Silbermann M, Arnaout M, Daher M, et al. Jordan pallaitve care initiative: A WHO demonstration project. J Pain Symptom Manage. 2007; 33(5): 628-633.

4. Mark S, Thomas H, Felicia K, et al. Innovation can improve and expand aspects of end-of-life care in low- and middle-income countries. Health Aff (Millwood). 2014; 33(9): 1612-1619. doi: 10.1377/hlthaff.2014.0379

5. Abdel-Razeq H, Attiga F, Mansour A. Cancer care in Jordan. Hematology/Oncology and Stem Cell Therapy. 2015; 8(2): 6470. doi: 10.1016/j.hemonc.2015.02.001

6. Al Hamarsheh M, Mrayyan M. Euthanasia for end stage cancer patients: A right to die? A policy brief. IOSR Journal of Nursing and Health Science. 2017; 6(1): 17-20.

7. Cultural and Spiritual Sensitive Palliative Care of Muslims, Yale Cancer Center. Web site. http://yalecancercenter.org/YCCANew\%20Transcript\%202015_239735_5.pdf. Accessed April $5,2017$.

8. D'emeh W, Yacoub M, Darawad M, Al-Badawi T, Shahwan B. Pain-related knowledge and barriers among Jordanian nurses: A national study. Health. 2016; 8: 548-558. doi: 10.4236/ health.2016.86058

9. Pettus K. Allaying fear of addiction, the main barrier to access to opioid medicines for palliative care. 2014. Web site. http:// www.ehospice.com/articleview/tabid/10686/articleid/11398/ language/en-gb/allaying-fear-of-addiction-the-main-barrier-toaccess-to-opioid-medicines-for-palliative-care.aspx. Accessed April 5, 2017.

10. Edrington J, Sun A, Wong C, et al. Barriers to pain management in a community sample of Chinese American patients 
with cancer. J Pain Symptom Manage. 2009; 37: 665-675. doi: 10.1016/j.jpainsymman.2008.04.014

11. Al Qadire M, Al Khalaileh M. Barriers to cancer pain management: Jordanian nurses' perspectives. International Journal of Palliative Nursing. 2012; 18(11): 535-536, 538-540. doi: 10.1016/j.jpainsymman.2008.04.014

12. Alaa B. Opioidphobia and cancer pain management. $J$ Pediatr Hematol Oncol. 2011; 33(1): S60-S61. doi: 10.1097/ MPH.0b013e3182122059

13. Al-Qadire M, Omran S, Tayyem M. Palliative care in Jordan: Accomplishments and challenges. In: Silbermann M, ed. Palliative Care to the Cancer Patient. Hauppauge, New York, USA: Nova Science Publish. 2014

14. Murray S, Osman H. Primary palliative care: The potential of primary care physicians as providers of palliative care in the community in the Eastern Mediterranean Region. East Mediterr
Health J. 2012; 18(2): 178-183.

15. Forgeron P, Finley G, Arnaout M. Pediatric pain prevalence and parents' attitudes at a cancer hospital in Jordan. $J$ Pain Symptom Manage. 2006; 31(5): 440-448. doi: 10.1016/j.jpainsymman.2005.09.003

16. Bushnaq M. Palliative care in Jordan: Culturally sensitive Practice. J Palliat Med. 2008; 11(10): 1292-1263. doi: 10.1089/ jpm.2008.0166

17. Shamieh O. Palliative Care in North Africa and the Middle East: Jordan perspectives. EPAC. 2016. Web site. https://eapcnet.wordpress.com/2016/05/18/palliative-care-in-north-africaand-the-middle-east-jordan-perspectives/. Accessed April 5, 2017.

18. Murray S. Meeting the challenge of palliation beyond cancer. European Journal of Palliative Care. 2008; 15: 213. 